\title{
Implementasi Highly Available Website Dengan Distributed Replicated Block Device
}

\author{
Mulyanto*1, Ahmad Ashari $^{2}$ \\ ${ }^{1}$ Jurusan Informatika, Fakultas Ilmu Komputer, UMRI, Riau \\ ${ }^{2}$ Jurusan Ilmu Komputer dan Elektronika, FMIPA UGM, Yogyakarta \\ e-mail: *11myanto@gmail.com, ${ }^{2}$ ashari@ugm.ac.id
}

\begin{abstract}
Abstrak
Sebagai sebuah infrastruktur IT yang penting, website merupakan sistem yang membutuhkan kehandalan dan tingkat availability yang tinggi. Website memenuhi kriteria sebagai sistem yang harus highly available karena website dituntut untuk memberikan layanan terhadap client secara real time, menangani data yang banyak dan tidak boleh ada kehilangan data ketika terjadi transaksi. Sistem yang highly available harus memenuhi syarat yaitu layanan tidak hanya mampu berjalan secara terus menerus, tetapi juga menjamin konsistensi terhadap permintaan data.

Pada penelitian ini akan dilakukan rancang bangun website yang memiliki sifat highly availability. Pendekatan yang dilakukan dengan membangun network cluster dengan fungsi failover dan replicated block device. Failover dibangun untuk memberikan ketersediaan layanan sedangkan replicated block device dimanfaatkan untuk memberikan kepastian terhadap konsistensi data pada saat terjadinya kegagalan terhadap layanan. Dengan pendekatan failover cluster dan replicated block device didapatkan cluster yang mampu menangani terjadinya kegagalan layanan web server maupun database server pada website.

Hasil dari penelitian ini, layanan website yang dibangun dapat berjalan dengan baik apabila terjadi kegagalan pada anggota node dari cluster. Sistem mampu memberikan tingkat availability pada layanan database server sebesar 99,999 (five nines) dan 99,98 (three nines) pada layanan web server.
\end{abstract}

Kata kunci_High Availability Website, Failover, Distributed Replicated Block Device

\begin{abstract}
As an important IT infrastructure, website is a system which requires high reliability and availability levels. Website meets the criteria as a highly available system because website must provide services to clients in real time, handle a large amount of data, and not lose data during transaction. A highly available system must meet the condition of being able to run continuously as well as guaranteeing consistency on data requests.

This study designed a website with high availability. The approach was building network cluster with failover and replicated block device functions. Failover was built to provide service availability, while replicated block device provides data consistency during failure of service. With failover cluster and replicated block device approaches, a cluster which is able to handle service failures of web server and database server on the website.

The result of this study was the services of the website could run well if there was any failure in node members of the cluster. The system was able to provide 99,999 (five nines) availability on database server services and 99,98 (three nines) on web server services.
\end{abstract}

Keywords—High Availability Website, Failover, Distributed Replicated Block Device 


\section{PENDAHULUAN}

\subsection{Latar Belakang Masalah}

Cebuah sistem dan infrastruktur IT yang harus selalu online seperti website, email, dan media Ne-learning merupakan sistem yang membutuhkan kehandalan. Ketika ukuran data tumbuh menjadi besar karena semakin banyak orang dan sistem yang berinteraksi, mengakibatkan pengelolaan data menjadi tidak efektif dan memiliki imbas terhadap kemampuan sistem untuk menyediakan layanan yang handal [1].

Syarat agar layanan highly available yaitu memiliki kecepatan kinerja, scalable, dan data yang terdistribusi [2]. Dalam menerapkan sistem yang high availability, banyak metode yang dapat dilakukan antara lain dengan melakukan pemisahan penyimpanan data. Tempat penyimpanan data dapat dibagi menjadi beberapa node. Hal ini berkaitan dengan mekanisme distribusi data yang digunakan oleh sistem dalam membagi-bagi data yang disimpannya ke dalam beberapa node.

Pada penelitian ini akan dilakukan rancang bangun website yang memiliki sifat highly available. Website memenuhi kriteria sebagai sistem yang high availability karena website harus memberikan layanan terhadap beberapa client secara realtime, menangani data yang banyak dan tidak boleh ada kehilangan data ketika terjadi transaksi [3]. High availability yang akan dibangun pada penelitian ini meliputi server-server yang berkorelasi dengan layanan website yaitu web server dan database server.

Website yang high availability dibangun dengan memanfaatkan protocol Heartbeat dan failover clustering. Heartbeat yang digunakan adalah Linux yaitu Corosync Cluster Engine dan replikasi data dengan Distributed Replicated Block Device (DRBD). Heartbeat dimanfaatkan untuk melakukan manajemen node sehingga mampu saling berkomunikasi dan melakukan sinkronisasi service yang berjalan. Sedangkan Distributed Replicated Block Device bekerja secara redundan dimana terdapat block device pada secondary server yang akan melakukan replikasi terhadap block data yang ada pada primary server. Penelitian perlu dilakukan untuk mengukur kepastian terhadap resiko kehilangan data dengan menggunakan konsep layanan recovery secara mirroring dan synchronous replication [4].

\subsection{Rumusan Masalah}

Dari latar belakang dan permasalahan yang telah disampaikan, permasalahan yang menjadi fokus penelitian ini adalah:

- Bagaimana merancang layanan website yang memiliki tingkat availability tinggi.

- Bagaimana mengimplementasikan website yang memiliki tingkat availability yang tinggi menggunakan failover clustering dengan pendekatan Distributed Replicated Block Device.

- Bagaimana perbandingan pada sistem high availability melalui pengujian availability sistem, waktu proses terhadap permintaan data (response time) dan kemampuan sistem terhadap beban kerja.

\subsection{Batasan Masalah}

Agar permasalahan tidak menjadi bias dan meluas, maka masalah yang diteliti akan dibatasi sebagai berikut:

- Sistem akan dibangun atas 2 (dua) node yang saling terhubung pada sebuah network cluster.

- Web server yang dipilih adalah Apache web server dengan database relational MySQL yang berjalan pada sistem operasi Linux 64-bit.

- Pengujian fungsional dilakukan dengan mengukur tingkat ketersediaan sistem (availability) dan pengujian beban dilakukan dengan bantuan tool Siege dimana jumlah simulasi pengguna konkuren dan perulangan pengujian ditentukan oleh penguji.

- Simulasi pengujian dilakukan hanya untuk menguji availability website yaitu web server dan database server pada local area network. 


\subsection{Tujuan}

Penelitian ini bertujuan untuk menyediakan sistem dengan kemampuan high availability pada website sehingga diharapkan dapat meningkatkan availability dalam melayani pertumbuhan dan permintaan data. Penelitian ini juga menguji tingkat availability dari sistem dengan menggunakan multi-node Distributed Replicated Block Device.

\subsection{Manfaat}

Adapun manfaat yang ingin diperoleh dari penelitian ini adalah memberikan kontribusi terhadap bagaimana implementasi sistem high availability dengan menggunakan failover clustering dan Distributed Replicated Block Device dan mendapatkan hasil pengujian yang tepat terhadap tingkat availability.

\subsection{Penelitian Terdahulu}

Penelitian Setyorini [5] tentang Rancang Bangun Sistem Informasi Akademik yang Fault Tolerance. Penelitian ini membahas perancangan dan pembuatan Sistem Informasi Akademik yang fault tolerance. Proses replikasi menggunakan passive replica dimana terdapat beberapa node dari server database yang menjadi slave dan melakukan replika terhadap server master.

Sedangkan Oei [6] melakukan penelitian terhadap toleransi kegagalan server database dilakukan dengan menggunakan server database slave yang merupakan replikasi dari server database pusat (master). Penelitian tentang database terpusat juga dilakukan oleh Angraini. Anggraini [7] melakukan penelitian tentang server database yang memiliki tingkat ketersediaaan tinggi (high availability) dan tingkat keandalan tinggi (high reliability) dengan menggunakan konfigurasi master slave database cluster dengan mekanisme failover.

Afif dan Suryono [8] melakukan penelitian untuk membangun Disaster Recovery Plan dengan DRBD. Implementasi dilakukan dengan server utama dan server backup yang ditempatkan pada data center yang berbeda.

Atmaja [1] melakukan penelitian tentang fragmentasi elastis multi-node pada database non-relasional untuk website forum diskusi. Hasil dari penelitian ini adalah sistem database yang memiliki availability dan scalability dengan menggunakan model database non-relasional.

Pada penelitian ini dilakukan implementasi multi-node Distributed Replicated Block Device dan failover clustring yang dimanfaatkan pada website untuk meneliti apakah availability yang tinggi dapat dicapai dengan menggunakan mekanisme clustering Distributed Replicated Block Device, dimana belum digunakan pada penelitian-penelitian sebelumnya.

\subsection{Landasan Teori}

Landasan teori merupakan teori-teori yang digunakan untuk memecahkan permasalahan. Pada bagian ini akan diuraikan teori-teori yang menjadi penunjang penelitian yang akan digunakan sebagai dasar dari pemecahan masalah.

\section{Availability}

Availability merupakan ukuran seberapa lama suatu service atau komponen-komponen dari service dapat segera digunakan. Availability merupakan properti yang digunakan sistem untuk tetap beroperasi bahkan ketika terjadi kegagalan proses [9]. Availability dapat juga didefinisikan sebagai kemungkinan bahwa sistem akan beroperasi dengan benar dalam waktu tertentu dan dapat menjalankan fungsinya bagi kepentingan client [10].

Availability selalu terkait dengan Service Level Agreement (SLA). SLA terdiri dari beberapa bagian yang mendefinisikan tanggung jawab terhadap tingkat ketersediaan layanan. Tingkat ketersediaan sistem diukur dari jumlah angka Sembilan (9). Semakin sedikit angka sembilan pada tingkat ketersediaan sistem maka semakin rendah pula availability sistem tersebut. Untuk aplikasi pada umumnya memiliki presentasi uptime $99 \%$ sudah dapat dianggap layak [11]. Perbandingan availability layanan terhadap presentase uptime ditunjukkan oleh Tabel 1. 
Tabel 1 Tingkat availability layanan [11]

\begin{tabular}{|l|l|l|l|}
\hline $\begin{array}{c}\text { Presentase } \\
\text { Uptime (\%) }\end{array}$ & \multicolumn{1}{|c|}{$\begin{array}{c}\text { Presentase } \\
\text { Downtime (\%) }\end{array}$} & \multicolumn{1}{|c|}{$\begin{array}{c}\text { Downtime } \\
\text { pertahun }\end{array}$} & \multicolumn{1}{c|}{$\begin{array}{c}\text { Downtime } \\
\text { perminggu }\end{array}$} \\
\hline 98 & 2 & 7.3 hari & 3 jam 22 menit \\
\hline 99 & 1 & 3.65 hari & 1 jam 41 menit \\
\hline 99,8 & 0,2 & 17 jam 30 menit & 20 menit 10 detik \\
\hline 99,9 & 0,1 & 8 jam 45 menit & 10 menit 5 detik \\
\hline 99,99 & 0,01 & 52.5 menit & 1 menit \\
\hline 99,999 & 0,001 & 5.25 menit & 6 detik \\
\hline 99,9999 & 0,0001 & 31.5 detik & 0.6 detik \\
\hline
\end{tabular}

Sistem High Availability

Sistem high availability biasanya dibangun untuk sistem yang memiliki tingkat toleransi kesalahan yang tinggi atau safety-critical. Layanan yang disediakan bersifat sangat penting, sehingga apabila terjadi kerusakan tidak akan menghentikan proses dalam sistem. Untuk membangun sistem yang high availability tidah hanya dibangun pada komponen yang tunggal akan tetapi melibatkan proses replikasi antara beberapa komponen. Jika ingin dibangun sistem yang high availability, maka tidak dapat tergantung hanya pada mesin tunggal, akan tetapi diperlukaan beberapa mesin independen dan dapat dilakukan perawatan secara fisik, pada salah satu anggota dari critical system [12].

\section{Network Cluster}

Cluster dapat didefinisikan sebagai sebuah sistem dari dua atau lebih sistem komputer independen dan subsistem penyimpanan yang saling berkomunikasi untuk tujuan membagi dan mengakses sumber daya [13]. Konsep sistem cluster didesain untuk meningkatkan tingkat kemampuan layanan. Cluster merupakan sekumpulan komputer yang saling berelasi dan bekerja bersama untuk menyelesaikan berbagai macam pekerjaan. Prinsip dari cluster adalah bahwa kumpulan komputer tersebut bekerja secara redundan sebagai sistem tunggal yang memiliki kemampuan yang lebih baik dibandingkan dengan komputer tunggal. Terdapat dua pendekatan yaitu failover cluster dan load balancing cluster.

\section{Failover Cluster}

Konsep konfigurasi failover cluster adalah membuat satu server sebagai primary server dan server yang lain menjadi secondary server dimana saat server dalam keadaan normal primary server menangani semua request dari client. Secondary server akan mengambil alih tugas master server apabila primary server gagal berfungsi. Implementasi cluster jenis ini akan mencoba untuk menggunakan redudansi komponen cluster untuk menghilangkan kegagalan disatu tititk (single point of failure). Failover cluster mengijinkan sebuah layanan untuk berpindah dari satu host ke host yang lain apabila terjadi error.

\section{Distributed Replicated Block Device}

Distributed Replicated Block Device (DRDB) merupakan mekanisme yang mirip dengan RAID dimana melakukan mirroring atau replikasi terhadap data. Jika RAID melakukan mirroring terhadap device to device terhadap media penyimpanan maka DRBD melakukan mirroring melalui jaringan. DRBD bekerja secara redundan dimana terdapat beberapa node melakukan replikasi dengan failover. Sinkronisasi antar node dilakukan dengan menggunakan mekanisme TCP/IP. Setiap node bekerja sebagai member dari cluster yang saling melakukan sinkronisasi. Singkronisasi dilakukan melalui jaringan. Arsitektur DRBD ditunjukkan pada Gambar 1. 


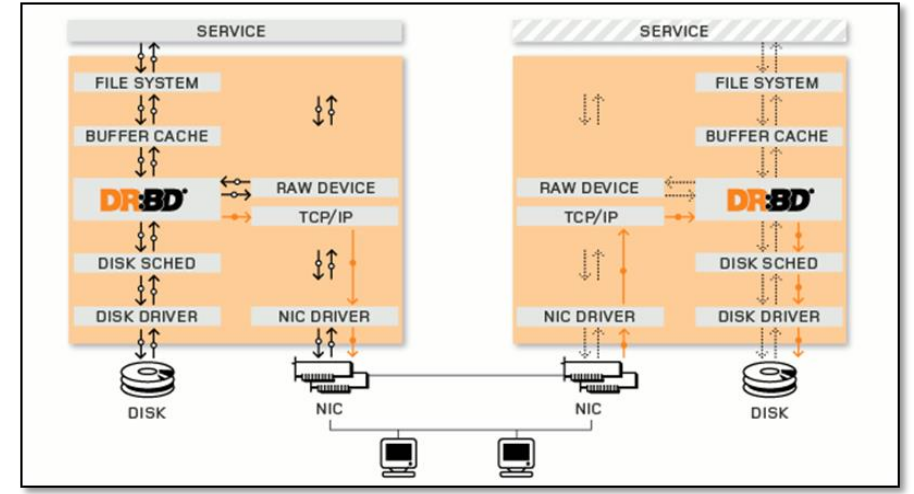

Gambar 1 Arsitektur Distributed Replicated Block Device [4]

Corosync Pacemaker

Pacemaker bertanggung jawab terhadap proses deteksi adanya failure pada node dan melakukan recovery pada node. Pacemaker juga bertanggung jawab terhadap monitoring infrastruktur pada cluster. Corosync bertanggung jawab dalam menyediakan layanan cluster service dalam bentuk class-class yang spesifik yang dapat diakses oleh pengguna melalui Application Pragrammable Interface (API). Corosync melakukan abstraksi terhadap engine cluster sehingga semua layanan dalam cluster dapat bekerja diatas lapisan dari Cluster Engine [14].

\subsection{Analisis}

\section{METODE PENELITIAN}

Failover yang akan dibangun pada penelitian ini merupakan failover cluster. Failover cluster yang dibangun memerlukan infrastuktur baik hardware maupun software. Topologi fisik sistem disimulasikan pada minimal 2 (dua) buah komputer yang saling terhubung dalam private Local Area Network (LAN). buah server yaitu server drbd1 sebagai node ke-1 dan server drbd2 sebagai node ke-2. Server drbd1 sebagai primary sedangkan server drbd2 sebagai secondary. Network cluster yang dibangun antar node dengan menggunakan Corosync Service Engine. Arsitektur perangkat keras ditunjukkan pada Gambar 2.

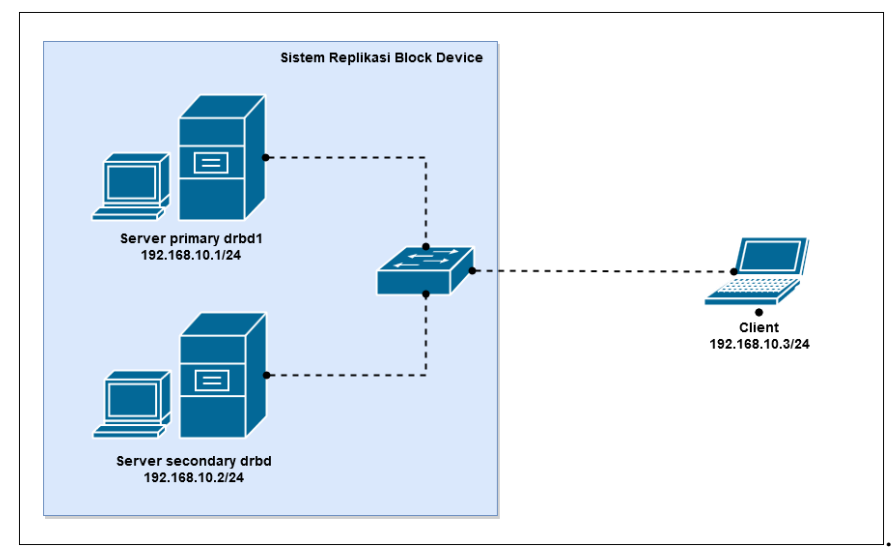

Gambar 2 Arsitektur perangkat keras

Setiap node akan di-install Corosyn dan Pacemaker sebagai software yang berfungsi untuk membangun network cluster. Sedangkan replikasi block device dengan memanfaatkan modul dari Linux yaitu Data Replicated Block Device (DRBD). Layanan website membutuhkan server yaitu web server dengan memanfaatkan Apache, sedangkan database server dengan menggunakan Database Management System MySQL. 


\subsection{Perancangan}

Pada tahapan ini dilakukan perancangan dan instalasi komputer-komputer pada suatu jaringan yang menghubungkan satu sama lain. Jaringan bersifat privat sehingga hanya menghubungkan komputer saja jaringan lokal. Perancangan pengujian system : Setelah sistem diimplementasikan, dilakukan pengujian untuk menjamin sistem yang dibangun dapat berjalan sebagaimana mestinya. Pengujian yang dilakukan meliputi pengujian tingkat availability dan pengujian beban.

\subsection{Implementasi}

Network cluster diimplementasikan dengan melakukan instalasi Corosync. Corosync berfungsi sebagai cluster yang akan melakukan kontrol terhadap node-node yang ada didalam sistem. Perlu untuk didefinisikan nama cluster dan node-node yang ada didalam sistem. Redundansi proses diimplementasikan dengan aktif-pasif failover cluster sekaligus berperan sebagai automatic failover sistem.

Implementasi Resource Cluster

Resource cluster merupakan layanan yang definisikan diatas cluster. Layanan dapat berupa aplikasi atau berupa data yang berjalan diatas cluster. Pada penelitian ini resource cluster yang dibangun antara lain Virtual IP, Web Server, MySQL, Filesystem dan DRBD. Konfigurasi resource pada cluster ditunjukkan pada Gambar 3.

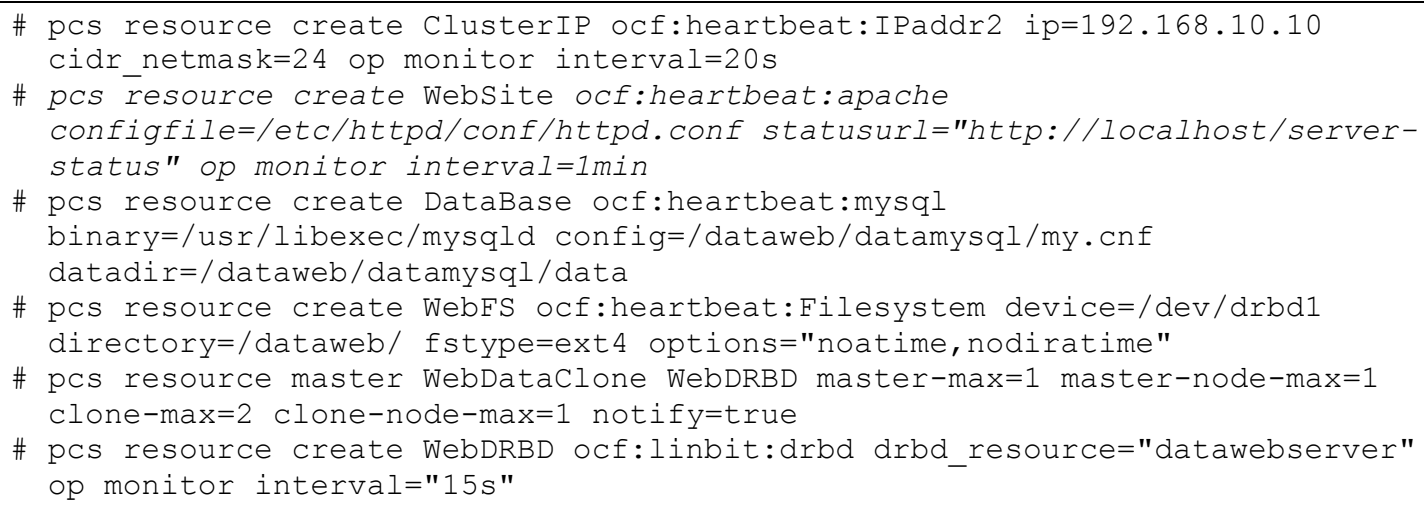

Gambar 3 Konfigurasi resource cluster

\section{Implementasi Failover Cluster}

Pacemaker dilakukan konfigurasi sebagai Cluster Resource Manager (CRM). Pada layer ini didefinisikan resource-resource yang akan dimonitor oleh Pacemaker. Resource cluster merupakan layanan yang definisikan diatas cluster. Layanan dapat berupa aplikasi atau berupa data yang berjalan diatas cluster. Resource cluster yang dibangun antara lain Virtual IP Address, Web Server, MySQL, Filesystem dan DRBD. Konfigurasi member pada cluster ditunjukkan pada Gambar 4.

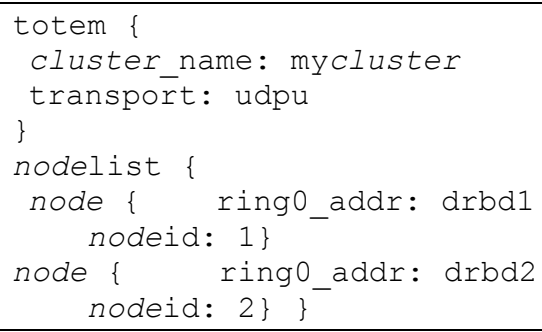

Gambar 4 Konfigurasi node anggota Corosync 
Implementasi Replicated Block Device

Replikasi block device diimplementasikan dengan menggunakan Data Replicated Block Device (DRBD). DRBD diimplementasikan sebagai bagian dari resource agent pada Pacemaker. DRBD dibangun dengan melakukan replikasi terhadap block data dari satu node ke anggota node lainnya pada cluster. Konfigurasi replikasi DRBD ditunjukkan pada Gambar 5.

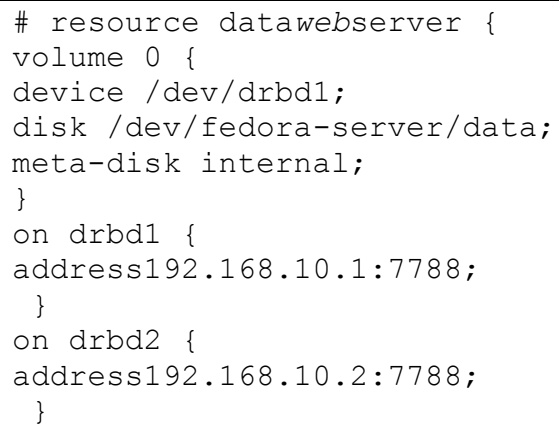

\section{Gambar 5 Script konfigurasi $D R B D$}

Implementasi Pengujian

Pengujian availability database dilakukan dengan mengirimkan query dari client. Pengujian availability database server dilakukan dengan memberikan input pada database server untuk menjalankan query. Program dibangun dengan menggunakan bahasa pemrograman Java. Adapun jenis query yang dilakukan adalah insert, update dan delete dengan jenis query yang digunakan adalah write dan read.

\section{HASIL DAN PEMBAHASAN}

\subsection{Hasil Pengujian Availability Database}

Pengujian dilakukan ketika primary server gagal memberikan layanan sehingga cluster akan memindahkan layanan ke secondary server. pengujian yang dilakukan adalah transaksi insert. Pada transaksi dilakukan pengujian dengan 10 kali pengujian. Pada transaksi insert dengan 1.000, 5.000 dan 10.000 transaksi didapatkan tingkat availability dari sistem sebesar 98,907, 99,800 dan 99,882. Hasil perbandingan availability pada transaksi insert ditunjukkan pada Tabel 2.

Tabel 2 Hasil perbandingan availability kegagalan transaksi insert

\begin{tabular}{|c|r|r|r|r|}
\hline Jenis Uji & Jumlah Data Input & \multicolumn{1}{|c|}{$\begin{array}{c}\text { Jumlah } \\
\text { Eksekusi }\end{array}$} & $\begin{array}{c}\text { Waktu Eksekusi } \\
(\mathrm{md})\end{array}$ & Availability \\
\hline \multirow{3}{*}{ Insert } & 1.000 & 994 & $91.383,50$ & 98,907 \\
\cline { 2 - 5 } & 5.000 & 4.995 & $310.414,80$ & 99,800 \\
\cline { 2 - 5 } & 10.000 & 9.994 & $1.023 .374,20$ & 99,882 \\
\hline
\end{tabular}

Pengujian transaksi update dilakukan dengan simulasi yang dilakukan tetap sama seperti pengujian insert, hanya saja query yang dilakukan diubah menjadi update. Perbandingan tingkat availability yang didapatkan untuk 1.000 adalah 99,026, untuk 5.000 didapatkan 99,808 dan untuk transaksi 10.000 diperoleh 99,896. Hasil perbandingan availability pada transaksi update ditunjukkan pada Tabel 3. 
Tabel 3 Hasil perbandingan availability kegagalan transaksi update

\begin{tabular}{|c|r|r|r|r|}
\hline Jenis Uji & Jumlah Data Input & Jumlah Eksekusi & $\begin{array}{c}\text { Waktu Eksekusi } \\
(\mathrm{md})\end{array}$ & Availability \\
\hline \multirow{3}{*}{ Update } & 1.000 & 995 & $40.961,00$ & 99,026 \\
\cline { 2 - 5 } & 5.000 & 4.995 & $165.473,50$ & 99,808 \\
\cline { 2 - 5 } & 10.000 & 9.994 & $794.513,10$ & 99,896 \\
\hline
\end{tabular}

Simulasi query delete tetap menggunakan 1.000, 5.000 dan 10.000 transaksi. Dengan hasil yang didapatkan yaitu 99,907, 99,764 dan 99,892 untuk pengujian dengan jumlah query $1.000,5.000$ dan 10.000 transaksi. Hasil perbandingan availability pada transaksi delete ditunjukkan pada Tabel 4.

Tabel 4 Hasil perbandingan availability kegagalan transaksi delete

\begin{tabular}{|c|r|r|r|r|}
\hline \multirow{2}{*}{ Jenis Uji } & Jumlah Data Input & Jumlah Eksekusi & $\begin{array}{c}\text { Waktu Eksekusi } \\
(\mathrm{md})\end{array}$ & Availability \\
\hline \multirow{3}{*}{ Delete } & 1.000 & 994 & $113.059,10$ & 98,907 \\
\cline { 2 - 5 } & 5.000 & 4.994 & $449.439,80$ & 99,764 \\
\cline { 2 - 5 } & 10.000 & 9.994 & $1.257 .266,40$ & 99,892 \\
\hline
\end{tabular}

Pengujian yang dilakukan pada saat terjadi kegagalan pada primary master. Semakin besar data yang akan diproses tingkat availability yang ditunjukkan sistem menjadi lebih besar, hal ini menujukkan bahwa kegagalan sistem bersifat konstan pada semua pengujian. Grafik perbandingan untuk pengujian insert, update dan delete dengan jumlah transaksi 1.000, 5.000 dan 10.000 ditunjukkan pada Gambar 6.

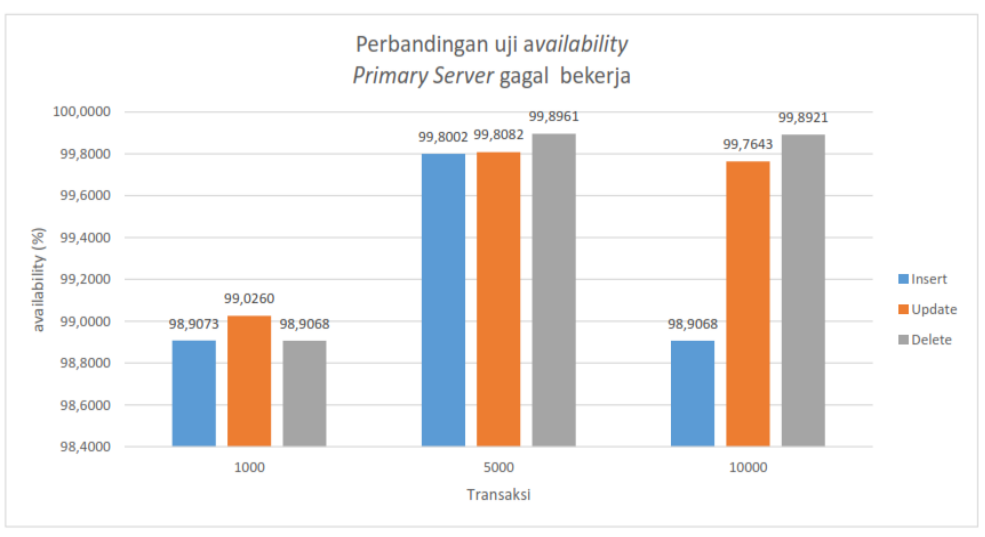

Gambar 6 Grafik perbandingan availability pada pengujian keseluruhan transaksi pada saat kegagalan sistem

\subsection{Hasil Pengujian Beban Database Saat Terjadi Kegagalan}

Pengujian beban database dilakukan dengan mengukur tingkat kemampuan server dalam menangani query dalam satuan waktu. Untuk query insert didapatkan pada pengujian yang pertama didapatkan tingkat availability sebesar 99,9991 sedangkan pada pengujian ke-2 didapatkan tingkat availability 99,9995 dengan rerata tingkat availability sebesar 99,9993. Hasil perbandingan beban pada transaksi insert ditunjukkan pada Tabel 5.

Tabel 5 Hasil pengujian beban database dengan transaksi insert

\begin{tabular}{|c|c|r|r|r|}
\hline No & $\begin{array}{c}\text { Waktu Eksekusi } \\
\text { (jam) }\end{array}$ & Berhasil (transaksi) & $\begin{array}{c}\text { Gagal } \\
\text { (transaksi) }\end{array}$ & Availability \\
\hline 1 & 24 & 1.358 .490 & 6 & 99,99912 \\
\hline 2 & 24 & 1.395 .872 & 3 & 99,99957 \\
\hline
\end{tabular}


Untuk pengujian update tingkat availability yang didapatkan sebesar 99,9995 untuk pengujian pertama dan 99,9993 pada pengujian kedua. Rerata availability pengujian sebesar 99,9994. Hasil perbandingan beban pada transaksi update ditunjukkan pada Tabel 6.

Tabel 6 Hasil pengujian beban database dengan transaksi update

\begin{tabular}{|c|c|r|r|r|}
\hline No & $\begin{array}{c}\text { Waktu Eksekusi } \\
\text { (jam) }\end{array}$ & Berhasil (transaksi) & $\begin{array}{c}\text { Gagal } \\
\text { (transaksi) }\end{array}$ & Availability \\
\hline 1 & 24 & 1.846 .908 & 4 & 99,99956 \\
\hline 2 & 24 & 1.804 .853 & 6 & 99,99933 \\
\hline
\end{tabular}

Untuk pengujian dengan query delete didapatkan hasil untuk pengujian pertama sebesar 99,9991 dan pengujian ke-2 sebesar 99,9992 dengan rerata availability pengujian sebesar 99,9994. Hasil perbandingan beban pada transaksi delete ditunjukkan pada Tabel 7.

Tabel 7 Hasil pengujian beban database dengan transaksi insert

\begin{tabular}{|c|c|r|r|r|}
\hline No & $\begin{array}{c}\text { Waktu Eksekusi } \\
\text { (jam) }\end{array}$ & Berhasil (transaksi) & $\begin{array}{c}\text { Gagal } \\
\text { (transaksi) }\end{array}$ & Availability \\
\hline 1 & 24 & 1.388 .880 & 6 & 99,99913 \\
\hline 2 & 24 & 1.374 .465 & 5 & 99,99927 \\
\hline
\end{tabular}

Dari pengujian beban dapat dilihat perbadingan tingkat availability terhadap query yang dikerjakan. Query update memiliki tingkat availability yang sedikit lebih baik dibandingkan dengan query insert maupun delete. Grafik perbandingan availability pada pengujian 24 jam ditunjukkan pada Gambar 7.

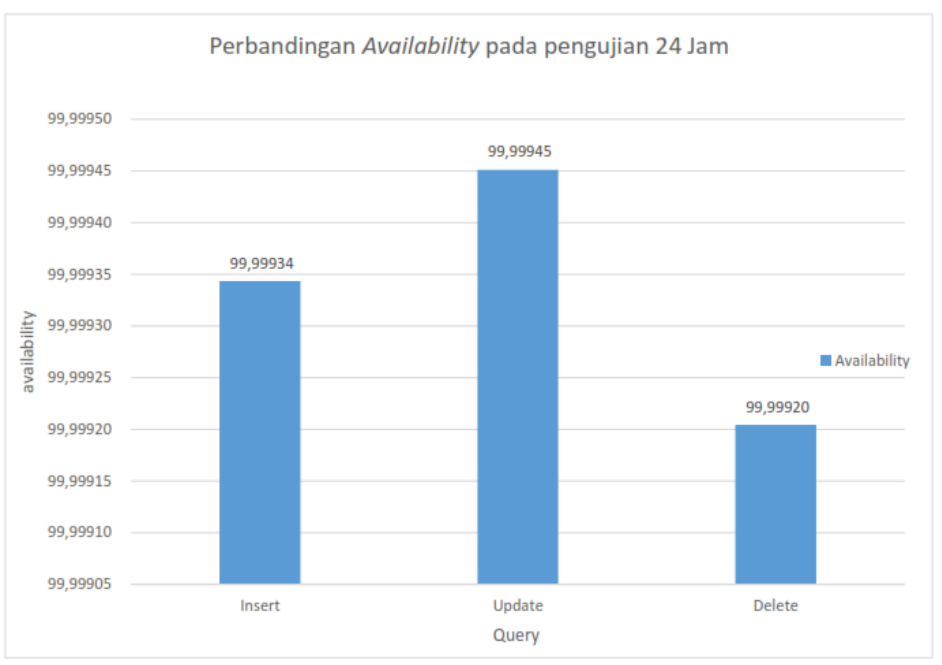

Gambar 7 Grafik perbandingan availability dengan transaksi insert, update dan delete pada pengujian 24 jam

\subsection{Pengujian Availability Web Server}

Web server memberikan layanan $100 \%$ jika tidak terjadi permasalahan pada cluster, sedangkan jika terjadi kegagalan sistem dimana primary server gagal maka akan dialihkan ke secondary server. Pada percobaan peralihan dari primary server ke secondary server, dengan percobaan selama 60 menit didapatkan tingkat ketersediaan sebesar 99,85 sedangkan pada 
percobaan yang lebih lama yaitu 24 jam, didapatkan hasil tingkat availability mencapat 99,992\%. Hasil perbandingan availability webserver pada transaksi ditunjukkan pada Tabel 8.

Tabel 8 Hasil perbandingan availability web server jumlah pengguna konkuren pada website

\begin{tabular}{|c|l|c|r|r|r|}
\hline No & \multicolumn{1}{|c|}{ Uji Kasus } & user & $\begin{array}{c}\text { Jumlah } \\
\text { Transaksi }\end{array}$ & $\begin{array}{c}\text { Transaksi } \\
\text { berhasil }\end{array}$ & $\begin{array}{c}\text { Availa } \\
\text { bility }\end{array}$ \\
\hline 1 & Pengujian website selama 60 Menit & 1 & 7.086 & 7.086 & 100 \\
\hline 2 & $\begin{array}{l}\text { Pengujian website dengan percobaan } \\
\text { konkuren user 50 selama 60 Menit }\end{array}$ & 50 & 580.068 & 580.068 & 100 \\
\hline 3 & $\begin{array}{l}\text { Pengujian website dengan percobaan } \\
\text { konkuren user 50 selama 60 menit dengan } \\
\text { terjadi kegagalan pada sistem }\end{array}$ & 50 & 340.134 & 339.880 & 99,85 \\
\hline 4 & $\begin{array}{l}\text { Pengujian website dengan percobaan } \\
\text { kegagalan sistem sebanyak 1 kali dalam } \\
\text { waktu 24 Jam }\end{array}$ & 50 & 8.195 .072 & 8.194 .752 & 99,992 \\
\hline
\end{tabular}

Pengujian diatas merupakan pengujian dengan memanfaatkan HTTP Request yang bersifat single request. Pada web dinamis proses login memanfaatkan session yang berfungsi untuk autentikasi user yang sedang memanfaatkan layanan. Pengujian menunjukkan bahwa failover tidak mempengaruhi session yang berjalan pada client. Pengujian pengaruh failover terhadap session ditunjukkan oleh Tabel 9.

Tabel 9 Hasil pengujian terhadap session ketika login ke web server

\begin{tabular}{|c|l|l|c|}
\hline No & \multicolumn{1}{|c|}{ Skenario Pengujian } & \multicolumn{1}{|c|}{ Keterangan } & Status \\
\hline 1 & User login ke sistem pada kondisi normal & $\begin{array}{l}\text { Session } \\
\text { konsisten }\end{array}$ & Berhasil \\
\hline 2 & $\begin{array}{l}\text { User login ke sistem pada saat secondary server } \\
\text { sebagai standby node }\end{array}$ & $\begin{array}{l}\text { Session } \\
\text { konsisten }\end{array}$ & Berhasil \\
\hline 3 & $\begin{array}{l}\text { Pengujian ketika terjadi kegagalan sistem, dimana } \\
\text { standby node berpindah dari primary server } \text { ke } \\
\text { secondary server }\end{array}$ & $\begin{array}{l}\text { Session } \\
\text { konsisten }\end{array}$ & Berhasil \\
\hline
\end{tabular}

\subsection{Pengujian Beban Web Server}

Pengujian dilakukan dengan melakukan simulasi dengan menggunakan pengguna yang dapat mengakses kehalaman website secara bersama-sama. Hasil pengujian pada sistem selama 24 jam memberikan hasil rata-rata sistem memiliki tingkat ketersediaan 99,9\% atau three fives pada uji coba HTTP Request. Hasil pengujian beban terhadap web server ditunjukan oleh Tabel 10.

Tabel 10 Hasil pengujian beban pada web server

\begin{tabular}{|c|r|r|r|r|r|}
\hline No. & Waktu Uji (Jam) & HTTP Request & Fault & Data Hits & Availability \\
\hline 1 & 24 & 2.443 .104 & 264 & 2.442 .840 & 99,978 \\
\hline 2 & 24 & 2.425 .392 & 278 & 2.425 .114 & 99,977 \\
\hline 3 & 24 & 2.471 .184 & 302 & 2.470 .882 & 99,976 \\
\hline 4 & 24 & 2.452 .752 & 383 & 2.452 .369 & 99,969 \\
\hline
\end{tabular}

Hasil pengujian pada sistem selama 24 jam memberikan hasil rata-rata sistem memiliki tingkat ketersediaan 99,9\% atau three fives pada uji coba HTTP Request. Grafik Pengujian yang dilakukan selama 24 jam ditunjukkan oleh Gambar 8. 


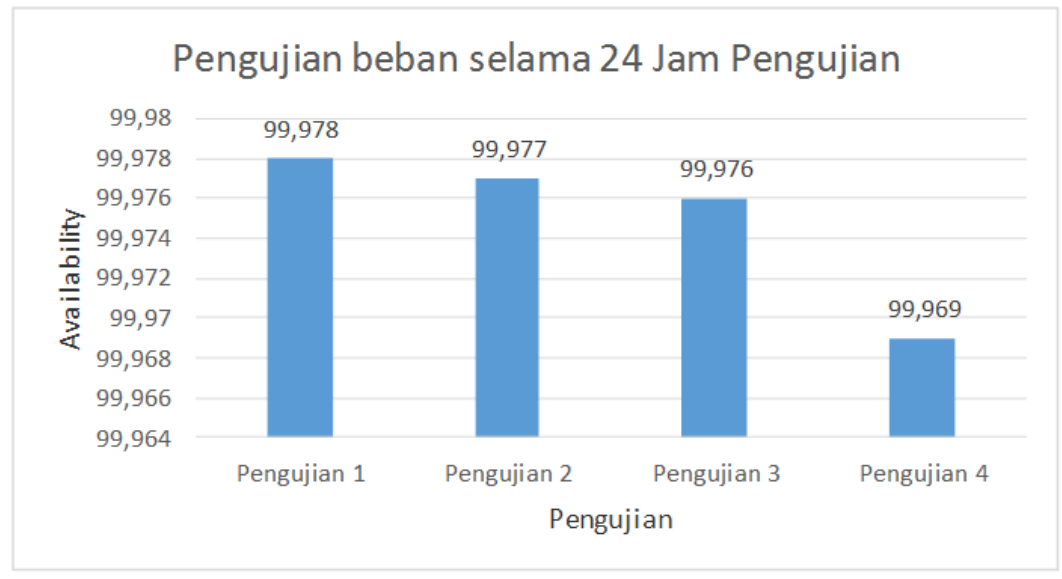

Gambar 8 Grafik pengujian beban web server

\section{KESIMPULAN}

Berdasarkan pada pembahasan yang telah diuraikan pada bagaian sebelumnya dapat ditarik kesimpulan yaitu:

- Pengimplementasian failover cluster dan replikasi data dapat menghasilkan Web server dengan tingkat availability yang tinggi, pada penelitian ini pengujian ketersediaan yang dapat dilayanani meliputi web server dan database server.

- Kegagalan pada pengujian web server terjadi pada HTTP request yang bersifat single request saja, proses session pada website tidak terpengaruh pada saat failover yang terjadi.

- Tingkat ketersediaan database mencapai 99,999 (five nines) sedangkan tingkat Ketersediaan terhadap website yang didapat mencapai 99,97 (three nines).

\section{SARAN}

Berdasarkan pengujian yang telah dilakukan, masih banyak kekurangan pada sistem sehingga perlu dikembangkan lagi agar kinerjanya lebih baik. Perlu untuk memperbaiki kinerja IP Virtual agar website dapat bekerja maksimal meskipun terjadi kegagalan sistem. Implementasi Network Cluster dan Distributed Replicated Block Device belum dapat memenuhi syarat sebagai sistem yang mission critical dimana memerlukan availability diatas 99,999 atau five nines.

\section{DAFTAR PUSTAKA}

[1] Atmaja, A. P., 2013, Tinjauan Implementasi Fragmentasi Elastis pada Database NonRelational untuk Website Forum Diskusi, Tesis, Magister Ilmu Komputer FMIPA Universitas Gadjah Mada, Yogyakarta.

[2] Paudyal, U., 2011, Scalable web application using node.JS and CaouchDB, Institutionen för informationsteknologi, Department of Information technology, Uppsala: Sweden.

[3] Lin, Z., 2009, Research and Implement of High Availability for Web Server Cluster System, Proceedings of 2009 Conference on Communication Faculty, Scientific Research, Beijing. 
[4] Ellenberg, L., 2009, DRBD 9 \& Device Mapper, Linux Block Level Storage Replication, LINBIT, Vienna, Austria.

[5] Setyorini, T. A., 2010, Rancang Bangun Sistem Informasi Akademik yang Fault Tolerance, Tesis, Magister Ilmu Komputer FMIPA Universitas Gadjah Mada, Yogyakarta.

[6] Oei, S., 2011, Rancang Bangun Fault Tolerance pada Sistem Database Pada Sistem Database Untuk Aplikasi Point Of Sale, Tesis, Magister Ilmu Komputer FMIPA Universitas Gadjah Mada, Yogyakarta.

[7] Anggraini, L. H., 2012, Rancang Bangun Highly Available dan Reliable Server Database dengan Automatic Failover, Tesis, Magister Ilmu Komputer FMIPA Universitas Gadjah Mada, Yogyakarta.

[8] Afif, M. F., Suryono, T., 2013. Implementasi Disaster Recovery Plan Dengan Sistem Fail over Menggunakan DRBD dan Heartbeat Pada Data Center FKIP UNS. Indonesian Jurnal on Networking and Security (IJNS) Volume 2 No 2 - April 2013 - ISSN: 2302-5700 (p. 6469).

[9] Schmidt, K., 2006, High Availability and Disaster Recovery Concepts, Design, Implementation, Springer-Verlag, Berlin.

[10] Tanenbaum, A. S. dan Steen, M. V., 2002, Distributed System Principles and Paradigms, Prentice Hall.

[11] Marcus, E., Stern, H., 2003, Blueprints for high availability $2^{\text {nd }}$ Edition, John Wiley \& Sons: Indianapolis.

[12] Depuydt, J., 2014, Building a high-available failover cluster with Pacemaker, Corosync \& PCS, http://jensd.be/?p=156, Diakses 24 April 2015.

[13] Lowe, D., 2005, Networking for Dummies, Seventh Edition, Wiley Publishing: New York.

[14] Dake, C. S., Caulfield, C., Beekhof, A., 2008, the Corosync Cluster Engine, Linux Symposium, Vol. 1, Ottawa, Ontario, Canada. 